\title{
Etiological factors and management in priapism patients and attitude of emergency physicians
}

\author{
Mehmet Giray Sönmez ${ }^{1}$, Leyla Öztürk Sönmez ${ }^{2}$, Hakkı Hakan Taşkapu ${ }^{1}$, Cengiz Kara ${ }^{3}$, \\ Zerrin Defne Dündar ${ }^{2}$, Yunus Emre Göğer ${ }^{1}$, Togay Evrin ${ }^{4}$, Ahmet Öztürk ${ }^{1}$ \\ ${ }^{1}$ Department of Urology, Meram Medical Faculty, Necmettin Erbakan University, Konya, Turkey; \\ ${ }^{2}$ Department of Emergency Medicine, Meram Medical Faculty, Necmettin Erbakan University, Konya, Turkey; \\ ${ }^{3}$ Department of Urology, Medical Park Ankara Hospital, Ankara, Turkey; \\ ${ }^{4}$ Department of Emergency Medicine, Ufuk University Medical Faculty, Ankara, Turkey.
}

\begin{abstract}
Summary Objective: To present the underlying etiological factors in patients referring with priapism, sharing how they are managed according to etiology and priapism type together with our experiences, creating awareness so that urologists and emergency physicians may play a more active role together in priapism management. Materials and methods: Patients referring to emergency service with priapism were examined. Penile Doppler ultrasonography (PDU) and/or corporeal aspiration and blood gas analysis were made in order to determine priapism type after anamnesis and physical examination. The most appropriate treatment option was chosen and applied on the patients considering priapism type, underlying etiological factors and priapism time.

Presence of a statistical difference between etiological factors causing priapism, priapism type and applied treatment methods was calculated using Chi square (X2) test.

Results: A total of 51 patients referring to emergency service with priapism attacks for 53 times were included in the evaluation. When compared to other etiological factors, number of priapism cases developing secondary to papaverine after PDU was found statistically significantly high $(p<0.001)$. Ischemic priapism ratio was detected statistically higher compared to other groups $(p<0.001)$. Aspiration and/or irrigation treatment were the most common method used for treatment at a statistically significant level $(p<0.001)$. All patients $(100 \%)$ were hospitalized in urology service without applying any treatment in emergency service and had treatment and intervention under the control of the urologist.

Conclusions: Application of non-invasive treatments in suitable priapism patients would protect patients from invasive painful interventions. We believe that emergency physicians should be more effective in priapism phase management and at least noninvasive treatment phase.
\end{abstract}

KEY WORDS: Priapism; Prolonged erection; Emergency.

Submitted 14 June 2017; Accepted 15 July 2017

\section{INTRODUCTION}

Priapism takes its name from god Priapus who is the symbol of virility and fertility in ancient Greek culture and is constantly in the state of erection (1). Priapism is a painful erection condition of penis or clitoris lasting more than four hours without sexual desire. Glans and corpus spongiosum do not participate in this period (2). Although observed rarely, it is one of the urological emergency pathologies. It is an urgency which may result in permanent erectile dysfunction unless treated quickly. Even though the incidence is rare (0.3$1.5 / 100.000)$, it is more common in males than females. It is frequent in 20-50 age group of males $(3,4)$.

Although the possible causes of priapism differ according to priapism types, it is observed that they are mostly related to idiopathic and iatrogenic causes. Alcohol, medicine, drug use (21\%), perineal trauma (12\%) and sickle cell nephropathy (5\%) are other possible etiological causes in order (4). Among iatrogenic priapism causes, penile papaverine application made for penile Doppler ultrasonography (PDU) used most commonly for erectile dysfunction diagnosis and use of phosphodiesterase 5 enzyme (PDE5) inhibitors used for erectile dysfunction treatment are responsible $(5,6)$. In order to be able to start priapism treatment, it is required to present priapism etiology primarily.

There are three different types of priapism: ischemic (veno-occlusive, low flow), non-ischemic (arterial, high flow) and stuttering (recurrent) priapism.

Pathophysiological causes and treatment methods of every priapism type are different (3)

Although priapism patients routinely refer to emergency service, patient management is frequently made by urologists. It is observed that generally emergency physicians demand urology consultation before intervening these patients.

The aim of this study is to present underlying etiological factors causing pathology in patients referring with priapism and sharing how these patients are managed according to the etiology and priapism type together with our experiences. At the same time, our aim was to create awareness so that emergency physicians may also actively participate in priapism management together with urologists.

\section{Materials AND METHOdS}

Without any relief through orgasm and ejaculation, erection state lasting longer than 4 hours was defined as priapism. Patients referring to emergency services between October 2006 and November 2016 were examined. A total of 51 patients referring to emergency service in two centers with a total of 53 priapism attacks were included 
in the evaluation. In the anamnesis of these patients, erection duration, previous priapism story, medicine, drug, alcohol use, phosphodiesterase type 5 inhibitor use (PDE5 inh), penile Doppler ultrasonography (PDU) story, penile papaverine and intracavernosal medicine application during or apart from PDU, presence of sickle cell anemia, trauma history, previous penile surgery, urinary system surgery and vertebra surgery story were questioned. All patients were examined physically after anamnesis. Continuation/discontinuation of erection, accompanying pain, presence of rigid erection, color of the penis, color and tissue changes for considering permanent circulation disorder in penis were evaluated. Penile Doppler ultrasonography and/or corporeal aspiration and blood gas analysis were made in order to determine priapism type. Blood count, prothrombin time and activated partial thromboplastin time were studied in order to evaluate possible hematological parameters in patients. The most appropriate treatment option was chosen and applied on the patients considering priapism type, underlying etiological factors and priapism time.

\section{Statistical analysis}

Statistical analysis was performed with SPSS 15.0 for Windows version 15.0 (SPSS Inc., Chicago, IL, USA). Presence of a statistical difference between etiological factors causing priapism, priapism type and applied treatment methods was calculated using Chi square test $(X 2) . \mathrm{P}<0.05$ was used as a threshold for statistical significance.

\section{RESULTS}

A total of 51 patients referring to emergency service in two centers with a total of 53 priapism attacks between October 2006 and November 2016 were included in the evaluation. Mean age of the patients was measured as 47.2 (10-69). Mean priapism duration was detected as 17.68 (5-104) hours. In relation to etiology, priapism was observed after Doppler ultrasonography (secondary to intracavernosal $60 \mathrm{mg}$ papaverine application) in 31 patients (60.7\%), after PDE5 inhibitor use in nine patients $(17.6 \%)$, secondary to urethral intervention in two patients (3.9\%), after pelvic trauma in two patients (3.9\%), pelvic mass related in one patient (1.88\%), antipsychotic drug use related in one patient (1.88\%) and related to unexplainable idiopathic causes since no cause was found in five patients (9.8\%). When compared to other etiological factors, number of priapism cases developing secondary to papaverine after PDU was found statistically significantly more frequent $(\mathrm{p}<0.001)$.

According to the penile Doppler ultrasonography and/or corporeal aspiration with blood gas analysis and the patient's clinic, four out of 53 priapism attacks (7.5\%) were stutter (two attacks each for two patients), three $(5.6 \%)$ were non-ischemic and 46 were ischemic priapism (86.7\%). Ischemic priapism ratio was detected statistically more frequently compared to other groups $(\mathrm{p}<0.001)$.
Table 1.

eneral information of patients.

\begin{tabular}{|c|c|c|}
\hline & & P value* \\
\hline lumber of patients & 51 & \\
\hline lumber of priapism attacks & 53 & \\
\hline lean age (years) & $47.2(10-69)$ & \\
\hline Mean priapism duration (hours) & $17.68(5-104)$ & \\
\hline \multicolumn{3}{|c|}{ lean hospitalization duration (hours) } \\
\hline & $19.2(4-215)$ & \\
\hline \multirow[t]{7}{*}{ tiology $(n=51)$} & PDU: 31 (60.7\%) & $<0.001$ \\
\hline & PDE 5 inh.: 9 (17.6\%) & \\
\hline & Idiopathic: 5 (9.8\%) & \\
\hline & Urethral intervention: 2 (3.9\%) & \\
\hline & Pelvic trauma: 2 (3.9\%) & \\
\hline & Pelvic mass: 1 (1.88\%) & \\
\hline & Antipsychotic drugs: 1 (1.88\%) & \\
\hline \multirow[t]{3}{*}{ riapism type $(n=53)$} & Ischemic: 46 (86.7\%) & \\
\hline & Non-ischemic: 3 (5.6\%) & \\
\hline & Stutter: 4 (7.5\%) & $<0.001$ \\
\hline
\end{tabular}

PDU: Penile Doppler ultrasonography;

PDE5: Phosphodiesterase 5 enzyme inhibitors; ${ }^{\star}$ Chi square $\left(\mathrm{X}^{2}\right)$ test.
In the etiology of non-ischemic type of patients, two patients had pelvic trauma and one patient had urethral intervention. Among two stutter type of patients, one had overdose PDE5 use and one had idiopathic etiology. General information for priapism patients are available in Table 1.

All patients (100\%) had urology consultation, were hospitalized in urology service without applying any treatment in emergency service and had treatment and intervention under the control of the urologist.

During the treatment of 53 priapism attacks, one nonischemic priapism patient with pelvic trauma etiology was treated with pudendal artery micro-embolization by interventional radiology, two patients with 4 stutter attacks were orally given pseudoephedrine $60 \mathrm{mg}+$ diazepam 5 mg+ketoconazole $200 \mathrm{mg}$ and two non-ischemic priapism patients were orally given pseudoephedrine $60 \mathrm{mg}$. Four ischemic priapism patients were given pseudoephedrine $60 \mathrm{mg}+$ diazepam $5 \mathrm{mg}$ medical treatment. But since detumescence was not provided, corporeal aspiration and/or phenylephrine irrigation were applied to a total of 46 patients including these four patients $(200 \mathrm{mcg} / \mathrm{ml}$, maximum: $1 \mathrm{mg}$ ). For corporeal aspiration and irrigation, a transcavernosal 18 Gauge needle was placed percutaneously into the lateral aspect of the proximal penile shaft. Aspiration and evacuation of blood from the corpora cavernosa were performed with irrigation of normal saline followed by irrigation with phenylephrine $(200 \mathrm{ug} / \mathrm{mL})$ in saline and administered intermittently as $1.0 \mathrm{~mL}$, every 3$5 \mathrm{~min}$ to a maximum dosage of $1 \mathrm{mg}$. Detumescence was provided in 39 patients through aspiration and/or irrigation. Spongiocavenous (distal) shunt was applied to seven patients unresponsive to aspiration and irrigation. Winter shunt and $\mathrm{T}$ shunt were applied as spongiocavernous shunt. Safenocavernous (proximal) shunt was applied to three patients not benefitting from this approach. Aspiration and/or irrigation treatment were the most common method used for treatment at a statistically significant 


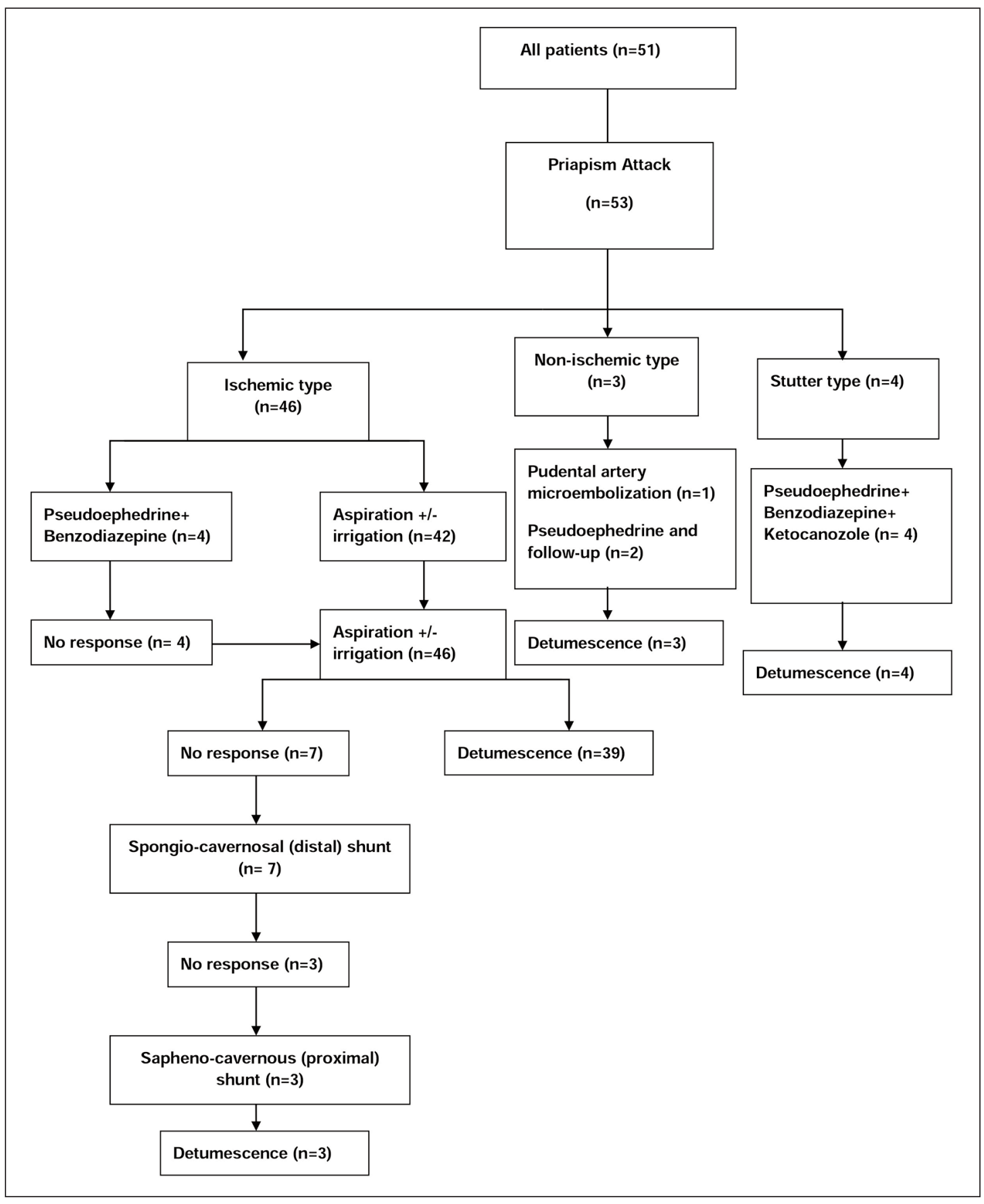

Figure 1.

Number of the patients and the study flow chart in each step.

level ( $<<0.001$ ). Mean hospitalization time of the patients was measured as 19.2 hours (4-215). Number of the patients and the study flow chart in each step are demonstrated in Figure 1.

\section{Discussion}

Priapism was published in 1845 for the first time in modern medicine literature (7). Recurrent priapism was defined in 1980 together with sickle cell anemia cases (8). After that it became a pathology covering a wide range of the studies in literature.

During the first referral of priapism patient, priapism duration, possible etiological factors, previous priapism story, presence of accompanying pain should be questioned and penile Doppler ultrasonography and/or corporeal aspiration with blood gas analysis should definitely be made in order to determine priapism type $(2,3)$. There are three different types of priapism: ischemic (veno-occlusive, low flow), non-ischemic (arterial, high flow) and stuttering (recurrent) priapism.

Pathophysiological causes and treatment methods of every priapism type are different. There is no or very low arterial flow in corpus cavernosum in ischemic priapism (IP). In non-ischemic priapism, cavernosal flow can be normal, high or irregular and arteriosinusoidal fistule or pseudoaneurism may be observed. Stuttering priapism has repetitive, spaced erections (1-4). Ischemic priapism 
is the most common type among priapism types. Ischemic priapism constitute $95 \%$ of all priapism cases. It is characterized by painful erection accompanied by significant permanent hardness in corpus cavernosum due to venous blood exit disorder. Occurrence of hypoxia, hypercapnia and acidosis is similar to penile compartment syndrome and this situation may cause tissue damage. In ischemic priapism, the ultrastructural changes in cavernosal flat muscle are observed 12 hours later, focal necrosis 24 hours later and finally necrosis and transformation of wide necrosis and fibroblast-like cells are observed 48 hours later.

Thus emergency inspection and management are required and delayed treatment may cause total erectile dysfunction (ED) (2-4). In the patient group in this study, ischemic priapism ratio was detected as $86.7 \%$.

There is an increase in priapism cases recently due to the frequent use of phosphodiesterase 5 enzyme (PDE5) inhibitors in ED treatment and to penile Doppler ultrasonography (PDU) generally accompanied by intracavernosal papaverine injection used for erectile dysfunction (ED) diagnosis. Prolonged erections after intracavornosal injection may be seen with a ratio of 5-35\% (9). In our priapism patient group, intracavernosal injection related priapism accounted for $60.7 \%$ and priapism developing after PDE 5 use for $17.6 \%$ of cases. All patients were using papaverine in priapism occurring due to intracavernosal injections. Idiopathic causes with a ratio of $9.8 \%$, urethral intervention and pelvic trauma with $7.5 \%$, antipsychotic drug use with $1.96 \%$ and pelvic mass with $1.96 \%$ played a role in etiology in this order. One of the most common causes of priapism is sickle cell disease (10). Interestingly, sickle cell disease was not detected as etiology in any of the patients in our group. This may be due to the fact that these patients were generally followed up by hematology department and were referred to their own hematologists or to child emergency service since they had their first attack between the ages 15 and 18 generally.

Suggestions of European Association of Urology guidelines and American Urological Association guidelines were used for the treatment of all patients $(2,11)$. Spontaneous resolution ratio is $62 \%$ with follow-up in non-ischemic priapism treatment and selective artery embolization can be made on demand (12). We followed up one patient with selective artery embolization and two patients with pseudoephedrine treatment in this group.

A complete response was obtained in all three patients. It is recommended to manage stutter priapism like priapism (13).

Medical agents such as pseudoephedrine, ketoconazole, GnRh agonists and 5-alpha reductase inhibitors were used for priapism attack and for preventing the attack (2, $12,14)$

We applied pseudoephedrine+benzodiazepine+ketoconazole medical treatment for our stutter priapism patients and we were successful in the treatment of four attacks. Time is important in ischemic priapism since serious complications may occur. So aspiration and/or irrigation should be the primary treatment. Primarily distal and then proximal shunt treatments should be used in irresponsive cases. Penile prosthesis may provide an effective treatment to preserve penile length in ischemic priapism patients not responding to conventional treatment (15). Penile prosthesis application was not required in any of the patients in this study.

Non-invasive treatment approaches are recommended for ischemic priapism in current studies. Habous et al. provided detumescence in 34\% of priapism patients in 60 minutes with salbutamol $4 \mathrm{mg}$ oral treatment which is a $\beta 2$ adrenergic agonist (9). Lowe and Jarow compared terbutaline which is a $X 2$ adrenergic agonist and pseudoephedrine which is $\beta$ - and $\beta 2$-adrenergic agonist in priapism patients and with a respond ratio of $38 \%$ with terbutaline and $28 \%$ with pseudoephedrine (16). Due to their antiandrogenic effect, gonadotropin-releasing hormone agonists, estrogens, anti- androgens and $5 \alpha$-reductase inhibitors can also be used as non-invasive medical treatment of priapism $(2,3)$. We recommend the use of these medicines in early-period priapism and stutter type priapism especially. This is due to the fact that delay in ischemic priapism treatment especially may result in permanent erectile dysfunction in the patient.

Especially in case of the patient being responsive to the application of symptomatic medicines such as terbutaline, salbutamol and pseudoephedrine during the first intervention in emergency service, the patient would be saved from an invasive intervention.

Emergency physicians generally leave priapism intervention to urologists in Turkey. In our study, treatment of all patients were managed by urologists. Since patients primarily refer to emergency service for priapism which is among the important urological emergencies, we believe that emergency physicians should have a good mastery of non-invasive and invasive treatment protocols for priapism and have equipment to provide required intervention on this.

\section{Conclusions}

Underlying etiological factors and priapism type should definitely be determined before starting priapism management. Application of non-invasive treatments in suitable patients would protect patients from invasive painful interventions. We believe that emergency physicians be more effective in priapism first phase management and at least in non-invasive treatment. Deficiencies during this phase may be made up through common education programs in urology and emergency medicine clinics.

\section{REFERENCES}

1. Kadıoglu A, Sanlı Ö, Ersay A, et al. Practical Management of Priapism. Turkish J Urol. 2006; 32:182-192.

2. Salonia A, Eardley I, Giuliano F, et al. European Association of Urology guidelines on priapism. Eur Urol. 2014; 65:480-9.

3. Shigehara K, Namiki M. Clinical Management of Priapism: A Review. World J Mens Health. 2016; 34:1-8.

4. Song PH, Moon KH. Priapism: current updates in clinical management. Korean J Urol. 2013; 54:816-23.

5. Coombs PG, Heck M, Guhring P, et al. A review of outcomes of 
an intracavernosal injection therapy programme. BJU Int. 2012; 110:1787-91.

6. Broderick GA, Kadioglu A, Bivalacqua TJ, et al. Priapism: pathogenesis, epidemiology, and management. J Sex Med. 2010; 7:476-500.

7. Tripe JW. Case of continued priapism. Lancet 1845; 2:8.

8. Emond AM. Holman R, Hayes RJ, Serjeant GR. Priapism and impotence in homozygous sickle cell disease. Arch Intern Med. 1980; 58:113-8.

9. Habous M, Elkhouly M, Abdelwahab O, et al. Noninvasive treatments for iatrogenic priapism: Do they really work? A prospective multicenter study. Urol Ann. 2016; 8:193-6.

10. Cita KC, Brureau L, Lemonne N, et al. Men with sickle cell anemia and priapism exhibit increased hemolytic rate, decreased red blood cell deformability and increased red blood cell aggregate strength. PLoS One. 2016; 11:e0154866.

11. Montague DK, Jarow J, Broderick GA, et al. Members of the
Erectile Dysfunction Guideline Update Panel; Americal Urological Association. American Urological Association guideline on the management of priapism. J Urol. 2003; 170:1318-24

12. Muneer A, Ralph D. Guideline of Guidelines Priapism. BJU Int. 2017; 119:204-208.

13. Muneer A, Garaffa G, Minhas S, Ralph DJ. The management of stuttering priapism within a specialist unit: a 25 years experience. British Journal of Medical and Surgical Urology. 2009; 2:11-16

14. Levey HR, Kutlu O, Bivalacqua TJ. Medical management of ischemic stuttering priapism: a contemporary review of the literature. Asian J Androl. 2012; 14:156-63.

15. Zacharakis E, Raheem AA, Freeman A, et al. Early insertion of a malleable penile prosthesis in ischaemic priapism allows later upsizing of the cylinders Scan J Urol. 2015; 26:1-4.

16. Lowe FC, Jarow JP. Placebo controlled study of oral terbutaline and pseudoephedrine in management of prostaglandin E1 induced prolonged erections. Urology. 1993; 42:51-3.

\section{Correspondence}

Mehmet Giray Sönmez, MD Assistant Prof (Corresponding Author)

drgiraysonmez@gmail.com

Hakkı Hakan Taskapu, MD Assistant Prof

Yunus Emre Göğer, MD Assistant Prof

Ahmet Öztürk, MD Prof

Department of Urology, Meram Medical Faculty,

Necmettin Erbakan University, Yunus Emre quarter,

42080 Konya, Turkey

Leyla Öztürk Sönmez, MD

Zerrin Defne Dündar, MD Associate Prof

Department of Emergency Medicine, Meram Medical Faculty,

Necmettin Erbakan University, Konya, Turkey

Cengiz Kara, MD Associate Prof

Department of Urology, Medical Park Ankara Hospital, Ankara, Turkey

Togay Evrin, MD Assistant Prof

Department of Emergency Medicine, Ufuk University Medical Faculty,

Ankara, Turkey 